\title{
LA PRETENSIÓN RESARCITORIA Y LA TUTELA JUDICIAL EFECTIVA DEL ESTADO EN LAS SENTENCIAS CONDENATORIAS DE PECULADO DE MOQUEGUA, 2016
}

\author{
CLAIM FOR DAMAGES AND EFFECTIVE ADMINISTRATION OF JUSTICE REGARDING \\ EMBEZZLEMENT CONVICTIONS IN MOQUEGUA, 2016.
}

\author{
Katerin Barrera Apaza ${ }^{1}$ \\ Investigadora independiente \\ Moquegua, Perú \\ https://orcid.org/0000-0003-1132-8688 \\ barreraapazak@gmail.com
}

\begin{abstract}
RESUMEN
La investigación se orientó a determinar en qué nivel el incumplimiento de la pretensión resarcitoria afecta el derecho de tutela judicial efectiva del Estado en las sentencias condenatorias de peculado del Distrito Judicial de Moquegua 2016. Investigación no experimental, de estudio transversal y de método lógico inductivodeductivo. La población estuvo conformada por los expedientes de ejecución de sentencias condenatorias firmes por el delito de peculado expedidas por la Corte Superior de Justicia de Moquegua en el año 2016; y, por los abogados de la Procuraduría Pública Anticorrupción de Moquegua. Los resultados obtenidos, permitieron establecer como conclusión principal que en un alto nivel el incumplimiento de la pretensión resarcitoria afecta el derecho de tutela judicial efectiva del Estado en las sentencias condenatorias de peculado del Distrito Judicial de Moquegua, 2016.
\end{abstract}

\section{PALABRAS CLAVES}

Estado, tutela judicial efectiva, pretensión resarcitoria, peculado.

\begin{abstract}
The purpose of this research is to determine how much the non-compliance of a judgment ordering damages affects the right to effective administration of justice in the embezzlement convictions in the Judicial District of Moquegua, 2016. Non-experimental research, cross-sectional study, and logical inductive-deductive methods were used. This study examined the writs of execution aimed at putting into force judgements handed down in connection with the crime of embezzlement by the Superior Court of Justice of Moquegua in 2016; and, by the lawyers from the Anti-Corruption Public Prosecutor's Office of Moquegua. The results allowed to conclude that the high level of non-compliance of judgements ordering damages affects the right to effective administration of justice in the embezzlement convictions in the Judicial District of Moquegua, 2016.
\end{abstract}

\section{KEYWORDS}

State, effective judicial protection, claim for damages, embezzlement

1 Abogada titulada con felicitaciones públicas por la Universidad José Carlos Mariátegui. Egresada de la Maestría Con Mención en Ciencias Penales por la Universidad Privada de Tacna. Asistente Judicial de la Sala Penal de Apelaciones de la Corte Superior de Justicia de Moquegua. Con ORCID: https://orcid.org/0000-0003-1132-8688 


\section{INTRODUCCIÓN}

Una de las preocupaciones de mayor relevancia en el sistema de justicia peruano es que todos los justiciables logren acceder a la justicia que tanto proclama el Estado Constitucional de Derecho, conforme reza el derecho subjetivo de la tutela judicial efectiva (Constitución, 1993, pág. 45). Sin embargo, cabe resaltar que este derecho no descansa únicamente en que los justiciables accedan a la justicia, sino que, además, una vez dictada la sentencia, se tenga la plena efectividad de sus pronunciamientos, es decir, se logre la eficacia de la sentencia (Gónzales Perez, 2001, pág. 57) (Sentencia del Tribunal Constitucional, 2008); pues, solo así, podremos afirmar que el derecho de tutela judicial efectiva desplegó todos sus efectos en el proceso, sea penal, civil, laboral, etc. De lo contrario, no tendría sentido recurrir a la instancia jurisdiccional, seguir todo un proceso judicial, para que, al fin al cabo, la sentencia que resuelve en definitiva el conflicto y/o incertidumbre jurídica no sea cumplida por la parte obligada, ocasionando que la contraparte no obligada no vea realmente solucionado su problema o, peor aún, resarcido los daños ocasionados por el adversario. Ya que, no serviría de mucho, tener una resolución firme en tu favor, si es que esta no la puedes hacer efectiva, quedándose solo en papeles el resultado de tu proceso.

En ese sentido, atendiendo que la tutela judicial efectiva, también llamada tutela jurisdiccional efectiva es un atributo subjetivo que comprende una serie de derechos entre los que se destacan el acceso a la justicia (derecho de cualquier justiciable de promover la actividad jurisdiccional del Estado, sin que se obstruya, impida o disuada irrazonablemente); también alcanza el derecho a la efectividad de las resoluciones judiciales, debiéndose garantizar la ejecución de lo resuelto, a fin de que las partes vean resarcido sus derechos tanto patrimoniales como extrapatrimoniales (Casación, 2008, pág. 33).

Empero, en estos últimos años, sucede algo singular en el proceso penal, sobre el extremo de la efectividad de las sentencias condenatorias, ¿acaso las sentencias que fijan obligaciones personales y reales al sentenciado están siendo cumplidas en su totalidad? Es una interrogante, que indudablemente en su mayoría de casos se responde con un no, específicamente cuándo nos referimos a la ejecución de las responsabilidades pecuniarias derivadas de los delitos contra la administración pública.

Pues, hace poco, la Procuraduría Pública Especializada en Delitos de Corrupción (PPEDC) puso de conocimiento a través de su portal, que quince altos funcionarios del gobierno de Alberto Fujimori, sentenciados por diferentes delitos vinculados a la corrupción, no han pagado ni la cuarta parte de sus obligaciones pecuniarias. Tal es así, que, en el caso de Alberto Fujimori, sentenciado por el delito de peculado doloso y usurpación de funciones, hasta la fecha no ha pagado ni una pecunia de los 27 millones 460 mil 216 soles que debe al Estado Peruano (Enco Tirado, 2020). De modo que, el ex presidente Alberto Fujimori, su ex asesor Vladimiro Montesinos y otros 13 sentenciados vinculados al régimen fujimontesinista que operó en los 90 aún tienen una deuda con el Estado por la suma de 1,405’200,390.89 soles (Valle, 2019).

Como es de notarse, el incumplimiento del pago de la reparación civil en los delitos de corrupción de funcionarios abarca millones de soles dejados de percibir por el Estado, pese a que, existe una sentencia condenatoria firme que ordena su pago, ocasionando una serie de perjuicios irreparables para el mismo.

Situación, que no es ajena para el Distrito Judicial de Moquegua, pues, conforme se desprende de las sentencias condenatorias firmes por el delito de peculado del año 2016, se tiene que, a la 
fecha, del total del pago de la reparación civil que oscila en $S / 539,176.99$ soles (Expediente $26-2013$ por S/12,000.00, Expediente 107-2011 por S/401,816.99, Expediente 197-2012 por S/123,000.00, Expediente 247-2013 por S/360.00 y Expediente 505-2014 por S/2,000.00), únicamente han pagado la cantidad de $S / 1,369.00$ soles, ni el $1 \%$ de la suma total de las reparaciones civiles condenadas en el año 2016. Por lo que, conforme se ha descrito, este incumplimiento de la pretensión resarcitoria afecta seriamente el derecho de tutela judicial efectiva del Estado. Ya que, al no verse efectivizado las decisiones judiciales finales del proceso penal, se vulnera de forma manifiesta este derecho, ocasionando, además, un alto perjuicio económico al Estado. Pues, al evidenciarse que, de las 05 sentencias condenatorias firmes, a la fecha se debe la cantidad de $S / 537,807.99$ soles, se manifiesta vulneración a su derecho constitucional de tutela judicial efectiva, ya que, el Estado no ve resarcido los daños sufridos por la comisión del delito de peculado, pese a contar con una sentencia condenatoria firme que le ampara exigir dicho pago.

Por consiguiente, resulta oportuno plantearnos el siguiente problema: ¿En qué nivel el incumplimiento de la pretensión resarcitoria afecta el derecho de tutela judicial efectiva del Estado en las sentencias condenatorias de peculado del Distrito Judicial de Moquegua 2016? En ese sentido, se pretende probar la siguiente hipótesis: En un alto nivel el incumplimiento de la pretensión resarcitoria afecta el derecho de tutela judicial efectiva del Estado en las sentencias condenatorias de peculado del Distrito Judicial de Moquegua 2016.

De modo que, la presente investigación resulta necesaria y pertinente, dado que, la afectación del derecho de tutela judicial efectiva por el incumplimiento de la reparación civil es un problema latente para nuestro sistema de justicia, porque, lamentablemente hasta la fecha el Estado en lugar de recuperar los activos que le fueron arrebatados ilícitamente, se encuentra a la espera de que algún día recuperará dichos activos, mientras tanto, su derecho de tutela judicial efectiva garantizado en el artículo 139, inciso 3 de la Constitución seguirá siendo vulnerado. Causando ello un impacto negativo a toda la sociedad, ya que los intereses del Estado en la administración pública forman parte de la sociedad.

\section{MATERIAL Y MÉTODOS}

\section{Diseño de la investigación:}

La presente investigación es de tipo descriptiva, desde un enfoque cuantitativo. Para la cual, se ha visto por conveniente aplicar el diseño no experimental, de estudio transversal, dado que, el estudio se realizará sin manipular las variables, únicamente serán observadas para después ser analizadas (Hernández Sampieri, Fernández Collado, \& Baptista Lucio, 2010, pág. 149).

\section{Población y muestra:}

Los criterios de inclusión y exclusión considerados para la delimitación poblacional son: sentencias condenatorias firmes expedidas en el año 2016 por la Corte Superior de Justicia de Moquegua, referidas al delito de peculado, que se encuentren en ejecución de sentencias; así como, los abogados que tienen la obligación de representar al Estado en los delitos de corrupción de funcionarios cometidos en el Distrito Judicial de Moquegua. Por lo que, el tamaño de la población asciende a 05 expedientes de ejecución de sentencias condenatorias firmes por el delito de peculado expedidas en la Corte Superior de Justicia de Moquegua en el año 2016; y, por 04 abogados de la Procuraduría Pública Anticorrupción Descentralizada de Moquegua (DS. № 0172008-JUS, 2008). 
De este número de expedientes y abogados, corresponde determinar la muestra de estudio. Sin embargo, atendiendo la reducida cantidad de la población; se puede acceder a ella sin restricciones. Por lo que, se ha optado por trabajar con toda la población en términos de justificación, para obtener un resultado real (Vara Horna , 2012, pág. 222).

\section{Técnicas e instrumentos de recolección de datos:}

Las técnicas de recolección para los 05 expedientes de ejecución fue la técnica de la observación y análisis; mientras que, para los 04 abogados fue la técnica de la encuesta, a fin de poder recopilar la opinión de la Procuraduría Pública Anticorrupción Descentralizada de Moquegua.

En ese sentido, para ser consecuente, también se han utilizado 02 instrumentos de medición: 1) La ficha de observación para los expedientes; y, 2) El cuestionario para los abogados.

La ficha de observación está dirigida para los expedientes de ejecución de sentencias condenatorias firmes por el delito de peculado 2016, y consta de tres partes: I. Datos generales $\left(\mathrm{N}^{\circ}\right.$ de expediente, Juzgado, Corte Superior, Imputado), II. Sentencia (Fecha, Delito, Fallo de primera instancia, de segunda instancia, pretensión civil a pagar), III. Ejecución de la sentencia (ejecución de la reparación civil, reparación civil dejada de pagar).

Es así que, a fin de medir "El incumplimiento de la pretensión resarcitoria", se ha tomado 03 ítems relevantes: 1) Pretensión civil sancionada, para su medición se previó la escala de variable de razón: monto de la reparación civil; 2) ¿Él o los sentenciados cumplieron con el pago de la reparación civil fijada en sentencia?, para su medición se previó la escala de variable nominal: SI y NO; 3) ¿A cuánto asciende la reparación civil dejada de pagar? para su medición se previó la escala de variable de razón: monto de la reparación civil adeudada.

Seguidamente, se ha utilizado el cuestionario para los abogados de la Procuraduría Pública Anticorrupción Descentralizada de Moquegua, a fin de medir la "Afectación del derecho de tutela judicial efectiva del Estado", para lo cual, se ha tomado 04 ítems relevantes: 1) ¿El incumplimiento del pago de la reparación civil afecta el derecho de tutela judicial efectiva del Estado? para su medición se previó la escala de variable nominal: SI y NO; 2) ¿En qué nivel el incumplimiento del pago de la reparación civil afecta el derecho de tutela judicial efectiva del Estado? para su medición se previó la escala de variable ordinal mediante el procedimiento de Likert: Muy alto - Alto Regular - Bajo; 3) ¿El incumplimiento del pago de la reparación civil ocasiona perjuicio económico al Estado? para su medición se previó la escala de variable nominal: SI y NO; y, 4) ¿En qué nivel el incumplimiento del pago de la reparación civil ocasiona perjuicio económico al Estado? para su medición se previó la escala de variable ordinal mediante el procedimiento de Likert: Muy alto Alto - Regular - Bajo.

Previo al procesamiento y análisis de datos se verificó la confiabilidad y validez de los instrumentos, para ello se ha tenido en cuenta la coherencia de los instrumentos con los resultados que se buscan en la investigación, por lo que, atendiendo que los instrumentos seleccionados, corresponden a una investigación ya realizada "Tesis: La ejecución de la reparación civil y la ausencia de incoación de medidas cautelares reales en las sentencias del delito de peculado, en la Corte Superior de Justicia de Moquegua en los años 2015-2017", se tiene mayor validez y fiabilidad para su aplicación en la presente investigación. 


\section{Procesamiento y análisis de datos:}

Para el procesamiento y análisis de datos se requerirá de un control estadístico descriptivo, empleándose para su representación tablas y gráficos mediante un programa computacional - hoja de cálculo de Microsoft Excel.

\section{RESULTADOS}

A continuación, se presentan los principales resultados de la investigación, los cuales se harán en función a las variables de investigación:

\section{La reparación civil de las sentencias condenatorias del delito de peculado 2016:}

Tabla 1: Reparación Civil

\begin{tabular}{ccccc}
\hline Exp. & Monto a pagar & \multicolumn{2}{c}{ Monto pagado } & Monto adeudado \\
\hline $26-2013$ & $\mathrm{~S} / 12,000.00$ & $\mathrm{~S} / 500.00$ & $4.17 \%$ & $\mathrm{~S} / 11,500.00$ \\
\hline $107-2011$ & $\mathrm{~S} / 401,816.99$ & $\mathrm{~S} / 0.00$ & $0.00 \%$ & $\mathrm{~S} / 401,816.99$ \\
$197-2012$ & $\mathrm{~S} / 123,000.00$ & $\mathrm{~S} / 0.00$ & $0.00 \%$ & $\mathrm{~S} / 123,000.00$ \\
\hline $247-2013$ & $\mathrm{~S} / 360.00$ & $\mathrm{~S} / 69.00$ & $19.17 \%$ & $\mathrm{~S} / 291.00$ \\
\hline $505-2014$ & $\mathrm{~S} / 2,000.00$ & $\mathrm{~S} / 800.00$ & $40.00 \%$ & $\mathrm{~S} / 1,200.00$ \\
\hline Total S/ & $\mathrm{S} / \mathbf{5 3 9 , 1 7 6 . 9 9}$ & $\mathrm{S} / \mathbf{1 , 3 6 9 . 0 0}$ & & $\mathrm{S} / \mathbf{5 3 7 , 8 0 7 . 9 9}$ \\
\hline Total \% & $\mathbf{1 0 0 . 0 0 \%}$ & $\mathbf{0 . 2 5 \%}$ & & $\mathbf{9 9 . 7 5 \%}$ \\
\hline
\end{tabular}

Fuente. Elaboración propia del autor.

En la tabla 1 se puede observar que en el año 2016 se expidieron 05 sentencias condenatorias por el delito de peculado, de las cuales, el Órgano Jurisdiccional condenó a los sentenciados a pagar una reparación civil, cuyos montos mas exuberantes datan de $S / 401,813.99, S / 123,000.00$ soles, cantidades elevadas que el Estado tiene que recuperar como parte de los daños patrimoniales y extrapatrimoniales sufridos. Empero, la suma total de las condenas de reparación civil asciende a un total de S/539,176.99 soles (equivalente al $100 \%$ ), de los cuales, únicamente el Estado a recuperado la cantidad de $S / 1,369.00$ soles (equivalente al $0.25 \%$ ), quedando una deuda de $S / 537,807.99$ soles. Asimismo, se observa que las condenas de reparación civil más elevadas (S/401,813.99 soles y $\mathrm{S} / 123,000.00$ ) hasta la fecha no se ha pagado ni una pecunia al Estado.

De tal forma que, del $100 \%$ de la reparación civil, solo se ha recuperado el $0.25 \%$, evidenciándose que el Estado a pesar de contar con una sentencia condenatoria en su favor, no logra hacer valer su derecho de tutela judicial efectiva, esto es, la ejecución total de la reparación civil.

Incumplimiento de la pretensión resarcitoria de las sentencias condenatorias del delito de peculado 2016:

Tabla 2: El incumplimiento de la pretensión resarcitoria

\section{Calificación Rango de pago Frecuencia observada Frecuencia relativa}

\begin{tabular}{cccc}
\hline Cumplimiento total & $100 \%$ & 0 & 0 \\
Cumplimiento parcial & $50 \%-99 \%$ & 0 & 0 \\
Incumplimiento & $0 \%-49 \%$ & 5 & 100 \\
\hline
\end{tabular}

Fuente. Elaboración propia del autor. 
Tabla 3: Sentencias que no pagaron el total de la reparación civil

\begin{tabular}{cccc}
\hline $\mathrm{N}^{\circ}$ & Opción de respuesta & Frecuencia & $\%$ \\
\hline 1 & $\mathrm{Si}$ & 0 & $0 \%$ \\
2 & $\mathrm{No}$ & 5 & $100 \%$ \\
Total & & 5 & $100 \%$ \\
\hline
\end{tabular}

Fuente. Elaboración propia del autor.

De la Tabla 2, se puede observar el análisis de los porcentajes de pago de la reparación civil, evidenciándose que el total de las 5 sentencias de peculado del año 2016 se encuentran en un rango de $0 \%$ al $49 \%$ de pago de la reparación civil, por lo que, su calificación de ejecución es de incumplimiento de la pretensión resarcitoria; dado que, el grado de ejecución del Exp. №26-2013 es de $4.17 \%$, del Exp. №107-2011 es de 0.00\%, del Exp. №197-2012 es de 0.00\%, del Exp. №2472013 es de 19.17\% y del Exp. N505-2014 es de 40\%; es decir, en ningún expediente de ejecución ni siquiera se llego a pagar el $50 \%$ de la reparación civil, por el contrario, la mayoría de expedientes esta por debajo del $4 \%$ de ejecución, por lo que, la calificación es de incumplimiento de la reparación civil. Así también, de la Tabla 3, de igual forma se aprecia que las 05 sentencias no han cumplido con el pago total de la reparación civil. Es decir, la ejecución de la reparación civil de las sentencias de peculado del 2016 son incumplidas por los sentenciados, pese a existir una obligación de dar al Estado.

Tabla 4: Inejecución de la reparación civil

\section{Ejecución de la reparación civil}

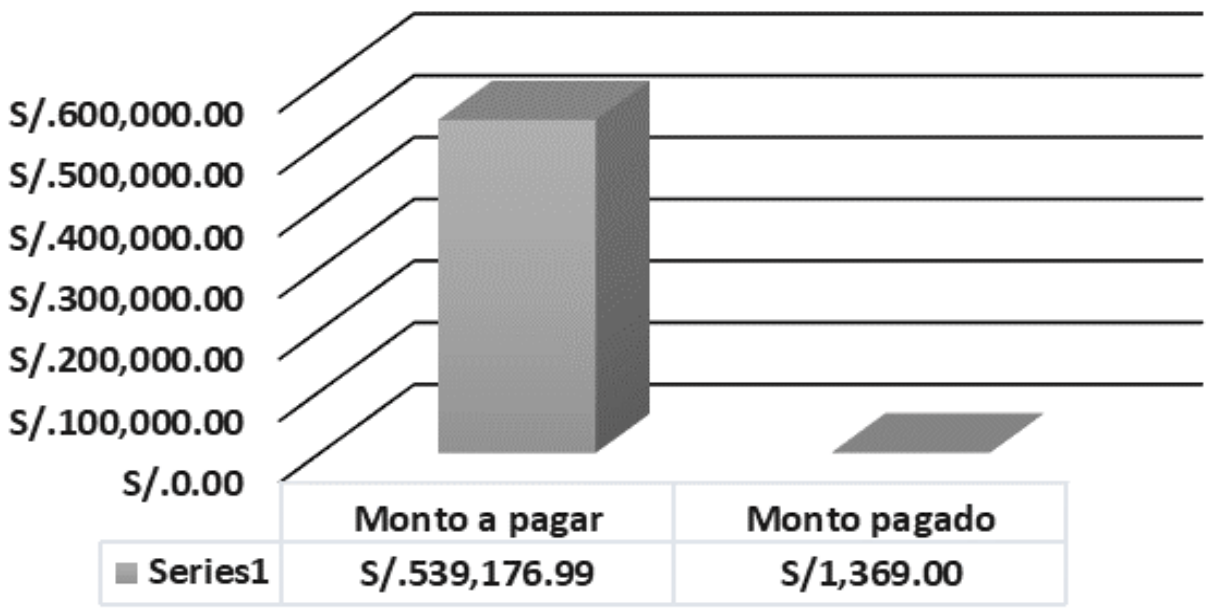

Fuente. Elaboración propia del autor.

Conforme se desprende del gráfico de barras, existe una diferencia abismal entre lo pagado y no pagado de la reparación civil. Pues, resulta una diferencia de $S / 537,807.99$ soles de deuda al Estado, la cual, a la fecha se encuentra a la espera de que algún día puedan ser pagadas; sin embargo, por el momento, dicho monto de dinero adeudado representa un atentado al derecho de tutela judicial efectiva del Estado, por no verse efectivizada la sentencia condenatoria firme. 
Nivel de afectación del derecho de tutela judicial efectiva del Estado de las sentencias condenatorias del delito de peculado 2016:

Tabla 5: Afectación de la Tutela Judicial Efectiva del Estado

\begin{tabular}{cccc}
\hline $\mathrm{N}^{\circ}$ & Opción de respuesta & Frecuencia & $\%$ \\
\hline 1 & $\mathrm{Si}$ & 4 & $100 \%$ \\
2 & $\mathrm{No}$ & 0 & $0 \%$ \\
& Total & 4 & $100 \%$ \\
\hline
\end{tabular}

Fuente. Elaboración propia del autor.

Tabla 6: Nivel de afectación del derecho de tutela judicial efectiva del Estado

\begin{tabular}{cccc}
\hline $\mathrm{N}^{\circ}$ & Opción de respuesta & Frecuencia & $\%$ \\
\hline 1 & Muy alto & 0 & $0 \%$ \\
2 & Alto & 4 & $100 \%$ \\
3 & Regular & 0 & $0 \%$ \\
4 & Bajo & 0 & $0 \%$ \\
\hline
\end{tabular}

Fuente. Elaboración propia del autor.

De la Tabla 5 se puede observar, que, para los 04 abogados de la Procuraduría Pública Anticorrupción Descentralizada de Moquegua, encargados de representar judicialmente al Estado en los delitos contra la administración pública, consideran que si existe una afectación al derecho de tutela judicial efectiva del Estado; es decir, el incumplimiento de las pretensiones resarcitorias si afecta al Estado, puesto que no ve resarcido los daños sufridos por el delito que fue materia de condena firme, manifestándose una latente vulneración al derecho constitucional previsto en el artículo $139^{\circ}$, inciso 3 de la Constitución Política del Perú.

Asimismo, en la Tabla 6, de igual forma los 04 abogados de la Procuraduría Pública Anticorrupción Descentralizada de Moquegua coinciden de que el nivel de afectación del derecho de tutela judicial efectiva para el Estado es alto; por lo que, el incumplimiento de la pretensión resarcitoria afecta en un nivel alto el derecho de tutela judicial efectiva del Estado en las sentencias condenatorias de peculado del Distrito Judicial de Moquegua 2016.

Tabla 7: Perjuicio económico del Estado

\begin{tabular}{cccc}
\hline $\mathrm{N}^{\circ}$ & Opción de respuesta & Frecuencia & $\%$ \\
\hline 1 & $\mathrm{Si}$ & 4 & $100 \%$ \\
2 & $\mathrm{No}$ & 0 & $0 \%$ \\
& Total & 4 & $100 \%$ \\
\hline
\end{tabular}

Fuente. Elaboración propia del autor. 
Tabla 8: Nivel del perjuicio económico al Estado

\begin{tabular}{cccc}
\hline $\mathrm{N}^{\circ}$ & Opción de respuesta & Frecuencia & $\%$ \\
\hline 1 & Muy alto & 0 & $0 \%$ \\
2 & Alto & 4 & $100 \%$ \\
3 & Regular & 0 & $0 \%$ \\
4 & Bajo & 0 & $0 \%$ \\
& Total & 4 & $100 \%$ \\
\hline
\end{tabular}

Fuente. Elaboración propia del autor.

Ahora bien, de la Tabla 7 se aprecia que los 04 abogados de la Procuraduría Pública Anticorrupción Descentralizada de Moquegua coinciden de que el incumplimiento del pago de la reparación civil indudablemente ocasiona perjuicio económico para el Estado, pues evidentemente, al no cobrar dicha pretensión civil, el Estado se queda sin resarcir los daños que trajo consigo la comisión de los ilícitos penales de peculado, manteniéndose el bien jurídico afectado económicamente. Así también, en atención a la Tabla 8, los abogados nuevamente armonizan de que en un nivel alto el incumplimiento de la reparación civil ocasiona perjuicio económico para el Estado, pues, al no hacerse efectivo la pretensión civil amparada y concedida en una sentencia firme, el Estado no se recupera y menos aún, resarce los daños patrimoniales y extrapatrimoniales ocasionados por los sentenciados.

\section{DISCUSIÓN}

Seguida de la exposición de los resultados y análisis de los datos, se ha logrado demostrar que en un alto nivel el incumplimiento de la pretensión resarcitoria afecta el derecho de tutela judicial efectiva del Estado en las sentencias condenatorias de peculado del Distrito Judicial de Moquegua 2016. Pues, a través de los datos recolectados como producto de la aplicación de la Ficha de Observación y el Cuestionario, se obtuvo como resultado que en las cinco (5) sentencias condenatorias (firmes) por el delito de peculado expedidas en el año 2016 que se encuentran en ejecución de sentencias existe un incumplimiento del pago de la reparación civil. Dado que, del 100\% del monto a pagar de la reparación civil hasta la fecha solo se ha cancelado el $0.25 \%$, es decir, ni el $1 \%$ ha logrado recuperar el Estado de sus caudales arrebatados ilícitamente. Por lo que, al no haber logrado llegar ni al rango de pago de cumplimiento parcial, la ejecución de las reparaciones civiles materia de investigación se han situado a un nivel de incumplimiento. Lo que evidentemente ocasiona una afectación al derecho de tutela judicial efectiva del Estado. En esa línea, también se ha logrado demostrar que el incumplimiento de las pretensiones resarcitorias afecta el derecho de tutela judicial efectiva del Estado en un nivel alto. Puesto que, los 4 abogados de la Procuraduría Pública Anticorrupción Descentralizada de Moquegua, encargados de representar judicialmente al Estado en los delitos contra la administración pública como el delito de peculado (MINJUS, 2019), han afirmado que evidentemente el hecho de que los sentenciados no cumplan con el pago de la reparación civil ocasiona indefectiblemente una vulneración al derecho de tutela judicial efectiva, pero que esa afectación es elevada "alta", puesto que aquí, el Estado para empezar no ve resarcido los daños materiales que trajo como consecuencia los delitos de peculado cometidos por los sentenciados, sino además, el Estado no está recibiendo de forma satisfactoria su derecho de tutela judicial efectiva, dado que, si bien, logro acceder a la justicia a través de su pretensión civil concedida, pero esta no se ha logrado hacer efectiva, pues, conforme ha establecido la Corte Suprema de Justicia de la República (Casación, 2017, págs. 04-06), este derecho despliega dos efectos: acceder a la 
justicia y la efectivización de las sentencias firmes. Por lo que, este último efecto en el presente caso no se ha materializado al no verse cumplido con el pago total de la reparación civil, ocasionando ello una alta afectación al derecho de tutela judicial efectiva del Estado.

Ahora bien, de los resultados obtenidos, es relevante resaltar que, de los pocos estudios relacionados al derecho de tutela judicial efectiva se encuentran grandes similitudes con la presente investigación. Tal es así, que, Martínez Cardoza (2016), en su Tesis "Vulneración a la tutela judicial efectiva en la concesión de medidas cautelares en el arbitraje peruano" concluyó que el derecho de la tutela judicial efectiva no se agota en el acceso de las partes al proceso, sino que además busca que lo resuelto en el proceso se efectivice, pues, de lo contrario, sino se logrará garantizar hacer efectiva la decisión contenida en el laudo final, se estaría afectando de forma directa el derecho de tutela judicial efectiva. Asimismo, coincidimos con Gónzales Perez (2001) en "El derecho de la tutela jurisdiccional" quien postulo que el derecho a la tutela efectiva abarca el acceso a la justicia y que los pronunciamientos de las sentencias sean efectivizados, a fin de que se pueda cumplir con satisfacción las pretensiones declaradas fundadas en un determinado proceso. Así también, el Tribunal Constitucional en sus pronunciamientos recaídos en los Exp. 763-2005-PA/TC y el Exp. 6963-2013-PA/TC ha establecido que la tutela judicial efectiva permite que las decisiones judiciales resulten eficazmente cumplidas; explicando que la tutela judicial efectiva no solo persigue asegurar la participación de los justiciables a los diversos mecanismos (procesos) que habilita el ordenamiento jurídico, sino que el resultado obtenido, pueda verse materializado.

En ese contexto, atendiendo que el derecho de tutela judicial efectiva consagrado en nuestra Constitución (artículo 139, inciso 3) es un derecho constitucional de índole procesal en merito al cual toda persona puede acceder a los órganos jurisdiccionales, pero, además, permite que la decisión judicial tomada en cualquier proceso resulte eficazmente cumplida. Es decir, lo decidido en la sentencia debe cumplirse, de lo contrario se vulnera este derecho constitucional, puesto que, no tiene sentido seguir un riguroso proceso para que una vez finalizado, no se pueda obtener el derecho otorgado y reconocido por el Juez. Por lo que, en los procesos penales, donde se persiguen 02 pretensiones (penal y civil), se requiere que ambas una vez reconocidas por una sentencia, sean efectivizadas al término del proceso.

Empero, conforme se ha observado en los resultados, las sentencias condenatorias firmes (por el delito de peculado) del 2016 de la Corte Superior de Justicia de Moquegua no están siendo cumplidas, puesto que, del total de la reparación civil a exigir, solo se le ha devuelto al Estado el $0.25 \%$, evidenciándose un incumplimiento sustancial de la reparación civil. Por lo que, si el extremo civil de la sentencia condenatoria no está siendo cumplido, se está ante una manifiesta vulneración del derecho de tutela judicial efectiva del Estado, situación que además para la presente investigación, ha sido reconocida por el representante judicial del Estado en los delitos de contra la administración pública (Procuraduría Descentralizada de Moquegua), quién además ha precisado que el nivel de la afectación es alto, dado que, con el incumplimiento de la pretensión civil no solamente se genera un perjuicio económico al Estado, conforme se ha probado, sino que además, ocasiona un desmedro tanto a la administración de justicia como a la administración pública, ya que, al no verse efectivizado ni siquiera el $1 \%$ de la reparación civil, se proyecta a la sociedad que el hecho que tengas una sentencia en tu favor, nada te garantiza que se vaya a cumplir, puesto que, si el mismo Estado no puede lograr recuperar los daños sufridos por un delito, menos un particular va a lograr ver resarcido los daños y perjuicios que le puede ocasionar un delito.

Por lo tanto, si se hace una visión genérica de los casos que actualmente cuentan con sentencias condenatorias por los delitos de corrupción de funcionarios, es muy probable que se encuentren 
en la misma situación que los que fueron materia de estudio, pues es una realidad imperante en nuestra sociedad que la comisión de este tipo de ilícitos penales cada día es mayor (La República, 2018), a tal forma de llegar institucionalizarse en el Estado (Mejía Tarazona, 2017), ocasionando una serie de afectaciones a la sociedad en general, pues los caudales o efectos que se sustraen del Estado no forman parte de un particular, sino es fruto de los impuestos que todos los ciudadanos pagamos para mantener operativo nuestro Estado (Perea Flores, 2018). Asimismo, no se debe perder de vista, que los perjuicios económicos que trae la corrupción oscilan en millones de soles que el Estado pierde, llegándole a costar al país un promedio anual de $4 \%$ de nuestro Producto Bruto Interno (PBI), pues de acuerdo a la cifras de la Contraloría General de la República, nuestro país pierde por corrupción estatal unos US\$ 3,000 millones al año (Enco Tirado, 2020) (Gran Angular, 2019). Por lo que, atendiendo la relevancia de este problema que vivimos día a día, sea como particulares cuando seguimos un proceso y no podemos ver resultados del mismo, o como sociedad, que no vemos que los sentenciados por delitos de corrupción devuelvan mínimamente el dinero sustraído, es menester hacer extensivo los resultados de la presente investigación, a fin de que los operadores de justicia y del Estado pongan atención a este problema e implanten y/o difundan los mecanismos que permitan hacer que las sentencias emitidas en un proceso realmente sean efectivizadas en todos sus extremos una vez emitidas. Porque es un escarnio a la justicia, que hasta la fecha, existan sentenciados por corrupción con penas punitivas a punto de cumplirlas, pero sin haber pagado en lo absoluto la reparación civil que se le condeno (caso Alberto Fujimori), ocasionando graves perjuicios patrimoniales (como los caudales y efectos sustraídos ilícitamente) y extrapatrimoniales (como el derecho de tutela judicial efectiva) para el Estado Peruano.

\section{CONCLUSIONES}

1. De acuerdo a los resultados positivos de la investigación, se puede afirmar que en un alto nivel el incumplimiento de la pretensión resarcitoria afecta el derecho de tutela judicial efectiva del Estado en las sentencias condenatorias de peculado del Distrito Judicial de Moquegua 2016. Debido a que, el Estado únicamente logra acceder a la justicia y obtener una sentencia en su favor, pero no logra obtener la efectividad de lo resuelto en la referida sentencia, respecto al extremo de la pretensión civil.

2. Asimismo, en atención a los resultados positivos de la investigación, se puede afirmar que en un alto nivel el incumplimiento de la pretensión resarcitoria ocasiona perjuicios económicos al Estado. Dado que, del 100\% (S/539,176.99) de la reparación civil sancionada, el Estado solo ha recuperado el $0.25 \%$, causándole un perjuicio del $99.75 \%$, el mismo que equivale a $\mathrm{S} / 537,807.99$ soles.

\section{REFERENCIAS}

- Binder M., A. (2018). Derecho Procesal Penal. Buenos Aires: AD-HOC SRL.

- Calderón Sumarriva, A. (2011). El nuevo sistema procesal penal: Análisis crítico. Lima: EGACAL.

- Casación N 1635-2008/Lima (Corte Suprema de Justicia de la República, 02 de diciembre de 2008).

- Casación N 864-2017/Huaura (Corte Suprema de Justicia de la República, 02 de diciembre de 2017).

- Constitución Política del Perú. (1993). Lima: Diario El Peruano.

- DS. No 017-2008-JUS. (2008). Reglamento del Sistema de Defensa Jurídica del Estado. Lima: Diario El Peruano. 
- Enco Tirado, A. D. (junio de 2018). procuraduriaanticorrupcion.minjus.gob.pe. Obtenido de https://procuraduriaanticorrupcion.minjus.gob.pe/wp-content/uploads/2018/08/INFORME-DEGESTION-2017.pdf

- Enco Tirado, A. D. (enero de 2020). procuraduriaanticorrupcion.minjus.gob.pe. Obtenido de https://procuraduriaanticorrupcion.minjus.gob.pe/wp-content/uploads/2020/06/RESUMENEJECUTIVO-DE-GESTION-2019-v03_.pdf

- Gónzales Perez, J. (2001). El derecho a la tutela jurisdiccional. Madrid: Civitas Ediciones S.L.

- Gran Angular. (2019). www.servindi.org. Obtenido de https://www.servindi.org/actualidadnoticias/28/10/2017/el-gabinete-del-cogobierno

- Hernández Sampieri, R., Fernández Collado, C., \& Baptista Lucio, P. (2010). Metodología de la investigación. México: Mc Graw Hill Educación.

- La República. (12 de agosto de 2018). larepublica.pe. Obtenido de https://larepublica.pe/ sociedad/1296884-corrupcion-sur-causo-s-93-millones-perdidas/

- Martínez Cardoza, L. (noviembre de 2016). pirhua.udep.edu.pe. Obtenido de https://pirhua. udep.edu.pe/bitstream/handle/11042/2669/DER_087.pdf?sequence=1\&isAllowed=y

- Mejía Tarazona, A. (09 de Febrero de 2017). América Latina en Movimiento. Obtenido de https://www.alainet.org/es/articulo/183418

- MINJUS. (10 de octubre de 2019). www.minjus.gob.pe. Obtenido de https://www.minjus.gob. pe/anticorrupcion/anticorrupcion-estructura-organizacional/

- Perea Flores, H. (10 de Septiembre de 2018). www.congreso.gob.pe. Obtenido de http://www. congreso.gob.pe/Docs/comisiones2018/Presupuesto/files/vice_economia_mef.pdf

- Prado Saldarriaga, V. (2000). Las consecuencias jurídicas del delito en el Perú. Lima: Gaceta Jurídica.

- Rojas Vargas, F. (2016). Manual operativo de delitos contra la administración pública cometidos por funcionarios públicos. Lima: Nomos \& Thesis.

- Rosas Yataco, J. (2018). Derecho procesal penal. Lima: CEIDES.

- Sentencia del Tribunal Constitucional, N 015-2001-Al/TC (Tribunal Constitucional, 29 de enero de 2004).

- Sentencia del Tribunal Constitucional, N 016-2001-Al/TC (Tribunal Constitucional, 29 de enero de 2004).

- Sentencia del Tribunal Constitucional, N 763-2005-PA/TC (Tribunal Constitucional, 13 de abril de 2005).

- Sentencia del Tribunal Constitucional, N 579-2008-PA/TC (Tribunal Constitucional, 05 de junio de 2008).

- Sentencia del Tribunal Constitucional, N 01797-2010-PA/TC (Tribunal Constitucional, 15 de noviembre de 2010).

- Sentencia del Tribunal Constitucional, Nº6963 2013-PA/TC (Tribunal Constitucional, 13 de agosto de 2014).

- Valle, F. (13 de enero de 2019). peru21.pe. Obtenido de https://peru21.pe/politica/albertofujimori-sentenciados-fujimontesinismo-le-deben-1-405-200-390-89-soles-452787-noticia/

- Vara Horna , A. A. (2012). 7 pasos para una tesis exitosa . Lima: Fondo Editorial de la Universidad de San Martín de Porres.

Fecha de recepción : 19 de octubre de 2021

Fecha de aceptación : 13 de noviembre de 2021 